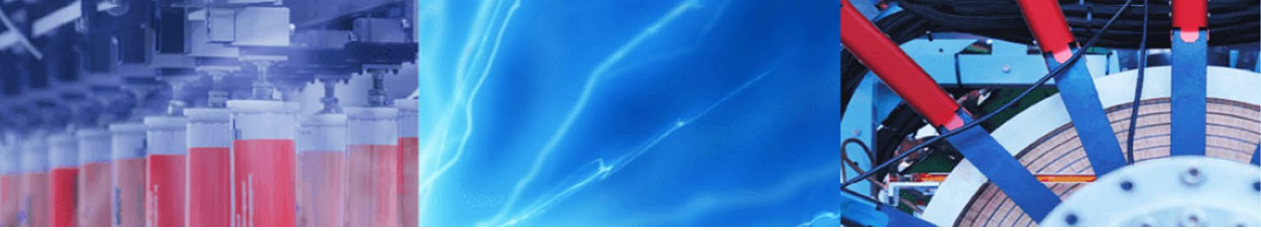

Research Article

\title{
Improving the nonlinear seismic performance of steel moment-resisting frames with minimizing the ductility damage index
}

\author{
Masoud Dadkhah $^{1} \cdot$ Reza Kamgar $^{1}$ (D) Heisam Heidarzadeh ${ }^{1}$
}

Received: 5 June 2020 / Accepted: 4 January 2021 / Published online: 11 January 2021

(c) The Author(s) 2021 OPEN

\begin{abstract}
In this paper, the parameters optimization of a tuned mass damper (TMD) is presented to enhance the seismic performance of a six-story steel structure based on the ductility damage index. Herein, the six-story frame is modeled nonlinearly in the OpenSees software by a concentrated plasticity model. Finally, the most suitable algorithm is selected among several optimization algorithms based on the convergence rate and the objective function's values. In this process, the water cycle algorithm has shown the best results. Therefore, the optimal parameters of the TMD are calculated by this algorithm in such a way that the ductility damage index is minimized in the six-story structure under earthquake loads. For this purpose, the nonlinear dynamic analysis of the structure is performed under earthquakes loads using the OpenSees software. Also, the optimum parameters of the TMD are computed to minimize the ductility damage index under the earthquake loads by linking the OpenSees and Matlab software. The results show that the optimum parameters of the TMD system obtained by the water cycle algorithm could appropriately decrease the ductility damage index. It can simultaneously increase the structure's seismic performance to reduce the displacement, stories damage, and drift ratio.
\end{abstract}

Keywords Tuned mass damper · Drift ratio · Powell damage index $\cdot$ Meta-heuristic algorithms $\cdot$ Nonlinear dynamic analysis

\section{Introduction}

The control of structures vibrations under wind and earthquake loads has been considered by many researchers [1, 2]. The tuned mass damper (TMD) has been introduced as one method for controlling the vibration of structures. In recent years, several meta-heuristic algorithms have been used by researchers to optimize their parameters (i.e., stiffness, mass, and damping coefficient) to minimize the values of roof displacement and drift in the stories. For this purpose, researchers have optimized the parameters of TMDs using various optimization algorithms $[3,4]$. Among the meta-heuristic algorithms, the charged system search algorithm (CSS), genetic algorithm (GA), gray wolf optimization (GWO) algorithm, harmony search (HS) algorithm, whale optimization algorithm (WOA), and improved gravitational search algorithm (IGSA) have been utilized to obtain the optimum parameters of the TMD system under earthquake loads [5].

The mean square displacement of the structure was minimized using the particle swarm optimization (PSO) algorithm. The maximum value of roof displacement was minimized using the optimum parameters of the TMD system subjected to the critical earthquakes [6]. Wong [7] studied the seismic energy dissipation for a nonlinear structure controlled with a TMD system. Wong showed that the TMD system could help the structure to save little energy during an earthquake. Also, the TMD system has been shown an increase in the value of dissipated energy. This helps reduce the formation of hysterical energy of the structure, which decreases the damage value of the structure. Therefore, the TMD system can effectively protect the

Reza Kamgar, kamgar@sku.ac.ir| 'Department of Civil Engineering, Sahrekord University, P.O. Box, 88186-34141 Shahrekord, Iran. 
structures from collapse during an earthquake. Shayesteh Bilondi et al. [8] enhanced the seismic performance of an especially moment-resisting frame subjected to an artificial earthquake. They showed that if the cumulative hysteretic energy is selected as the objective function, the best seismic response is observed during the earthquake. Shu et al. [9] studied the optimal design of an equivalent pendulum-type TMD system subjected to the seismic load.

Researchers have proposed some criteria to compute structures damage $[10,11]$. At present, the failure of the structures under critical earthquake loads is one of the essential and valuable issues in the scope of structural and earthquake engineering. Also, various parameters have been introduced to compute the damage of the structure. These criteria introduce a number called the damage index, which describes the concept of failure using a suitable theory. The structural behavior is investigated with nonlinear analysis to detect the structural vulnerability, and finally, the damage index is calculated using the obtained results and analytical relationships. The most straightforward damage index has been presented by Powell and Allahabadi [12]. This criterion is known as the ductility index. Williams and Sexsmith [13] gave a new formula to compute the damage index in reinforced concrete structure based on the energy concept. Cosenza et al. [14] combined the ductility and energy criteria to compute the damage index. The maximum displacement value was combined with the plastic energy dissipation value to calculate the reinforced concrete structures' damage index [15]. According to the theory presented by the Park and Ang, the total dissipation energy of the structure does not coincide with its final ductility. In other words, when the energy of the structure is completely dissipated, the ductility cannot be reached its ultimate level, and vice versa. Recently, Díaz et al. [16] proposed the capacitybased damage indices for steel structures. In each of the papers, as mentioned earlier, an index has been presented to determine the amount of damage to the structure by considering an aspect of structural behavior. Colombo and Negro [17] presented a general damage index based on the deterioration of resistance capacity. Zhang et al. [18] introduced an index to compute the amount of structural damage using the force analogy method. Gholizadeh and Fattahi [19] studied the damage parameter for an optimally designed steel moment frame. Danesh et al. [20] evaluated the seismic collapse capacity of a steel moment frame optimized using performance-based design optimization.

In this paper, the TMD parameter optimization has been presented to decrease the Powell damage index. For this purpose, a six-story steel frame that has been previously studied by numerous researchers is selected and modeled with the OpenSees software. The frame is modeled nonlinearly by a concentrated plasticity model using the Ibarra-Medina-Krawinkler (IMK) model [21, 22], and the results are verified with the previous studies. The most suitable algorithm is selected among PSO, GWO, WCA, and ICA based on convergence speed and optimal response aspects. The results show that WCA is the most suitable algorithm. Then, the optimum values for the parameters of the TMD system are obtained subjected to the earthquake loads in such a way that the Powell damage index is minimized. The results show that the optimum values for the parameters of the TMD system obtained by the water cycle algorithm could appropriately decrease the Powell damage index. It can simultaneously increase the seismic performance of the structure to reduce the displacement and drift of the stories.

\section{Ductility damage index (DDI)}

The Powell damage index [12] (or the ductility damage index) can be computed as follows:

if $d \leq d_{y}$ then $D=0$

if $d_{y} \leq d \leq d_{u}$ then $D=\left(\frac{d-d_{y}}{d_{u}-d_{y}}\right)$

where $D, d, d_{y}$, and $d_{u}$ show the damage index, the damage parameter, the limit, and the ultimate values for damage parameter, respectively. These parameters can be presented in the form of deformation, displacement, or energy dissipation. The damage parameter can be formulated based on the ductility criterion as follows:

$d=\left(\frac{x_{\max }}{x_{y}}\right)$

where $x_{\max }$ and $x_{y}$ show the maximum and yield displacements of the structure. The value of $x_{\max }$ can be obtained from a nonlinear dynamic analysis, while the pushover analysis may be used to compute the value of $x_{y}$. Besides, the value of $d_{u}$ is the ultimate ductility of the structure and should be obtained from the pushover [12]. There is some published literature in determining the accuracy and efficiency of dynamic analysis methods [23].

\section{Optimal design of the TMD system}

In recent decades, the devastating earthquakes have led to an increase in human death due to the buildings' collapse. The destruction of high-rise structures makes it inevitable to use control vibration devices. Therefore, research and 
development of seismic control techniques of structures are significant to improve the response of buildings to lateral forces [24]. Seismic response control is now a method of designing structures that has been widely accepted by civil engineers. The control methods include (1) active, (2) semi-active, (3) passive, and (4) hybrid. In passive control systems, the characteristics of the control system do not change. In contrast, in the active control systems, the structure response is reduced by external energy. The performance of the active control systems is more than passive control systems.

The tuned mass dampers (TMDs) fall into the category of passive control systems. This system consists of mass, spring, and damping. The structure's responses reduce when the damper frequency is set close to the fundamental frequency of the main structure. In this way, the TMD is positioned in a phase opposite to the motion of the structure. Therefore, the meaningful part of the input energy is damped by the damper and reduces the dynamic response of the structure. Figure 1 presents a single degree of freedom (SDOF) system equipped with a TMD system.

Here, the optimization of TMD parameters (i.e., coefficient damping $C_{d}$, mass $M_{d}$ and stiffness $K_{d}$ ) is studied to minimize the ductility damage index under the earthquake load. Thus, the optimization process can be formulated as follows:

Find : $\quad M_{d}, K_{d}, C_{d}$

Minimize: $\quad D\left(M_{d}, K_{d}, C_{d}\right)$

Subjected to : $M_{d}^{\min } \leq M_{d} \leq M_{d}^{\max }$

$$
\begin{aligned}
& K_{d}^{\min } \leq K_{d} \leq K_{d}^{\max } \\
& C_{d}^{\min } \leq C_{d} \leq C_{d}^{\max } \\
& \max \left(\left|u_{d}(t)-x_{\text {Roof }}(t)\right|\right) \leq s t_{\max }
\end{aligned}
$$

In Eq. (4), the $M_{d}^{\text {min }}$ parameter shows the lower bound of the TMD mass, while $M_{d}^{\text {max }}$ represents the upper bound for this parameter. Also, $K_{d}^{\min }$ and $C_{d}^{\min }$ parameters represent the lower bounds of the TMD spring constant and damping constant, respectively. Besides, the $K_{d}^{\max }$ and $C_{d}^{\max }$ show the upper bounds of the TMD spring constant and

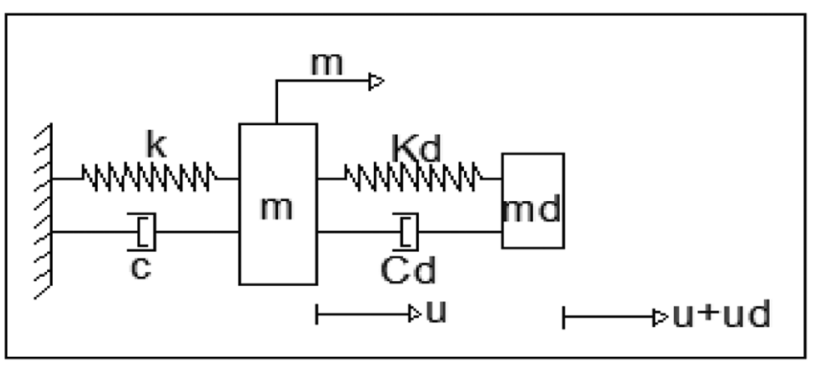

Fig. 1 An SDOF system equipped with the TMD system damping constant, respectively. These values are selected based on Ref. [8] and listed in Table 1.

The design constraint defined in Eq. (4) is considered as the stroke capacity of the TMD system and is limited to a user-defined value, $s t_{\max }$. In this paper, the parameter $s t_{\max }$ is selected to be $1000(\mathrm{~mm})$.

\section{Meta-heuristic algorithms}

\subsection{Imperialist competitive algorithm (ICA)}

The ICA starts with several randomly initial populations, which each of them is called a country. Detailed information can be found in [25].

\subsection{Adaptive weight particle swarm optimization (AWPSO)}

The social behavior of animals has been used to create the PSO algorithm. This algorithm consists of several randomly selected particles in the search space. Each particle's position is searched in the search space based on the best individual situation of each particle and moves toward the best position of the particle in the set. Complete information can be found at [26].

\subsection{Gray wolf optimization (GWO)}

The natural process of gray wolves hunting was utilized to create the GWO algorithm. The gray wolves hunting is consists of three main hunting steps (i.e., search, siege, and attack). It should be noted that the process of gray wolves hunting is done by four wolf gray named $\alpha, \beta, \delta$, and $\omega$. In this method, the first, second, and third solutions are $\alpha, \beta$, and $\delta$, respectively. Finally, the other remaining candidates will be considered as $\omega$. Detailed information can be found in Ref. [27].

\subsection{Water cycle algorithm (WCA)}

The flow of streams toward the sea was utilized by Eskandar et al. [28] to create the WCA. The flow of water is like the root of a tree. In this regard, the small rivers are liked by the small branches of this stream. A combination

Table 1 The selective bounds of the design variables

\begin{tabular}{lcc}
\hline The parameters of the TMD & Lower bound & Upper bound \\
\hline$K_{d}(N / \mathrm{mm})$ & 0 & 40,000 \\
$C_{d}\left(N \cdot \mathrm{sec}^{\prime} \mathrm{mm}\right)$ & 0 & 2000 \\
$M_{d}\left(\mathrm{~N} \cdot \mathrm{sec}^{2} / \mathrm{mm}\right)$ & 9000 & 180,000 \\
\hline
\end{tabular}


of these rivers forms the sea with the lowest elevation. Detailed information can be found in Ref. [28].

\section{Modeling of six-story steel moment-resisting frame}

This section presents a six-story steel moment-resisting frame studied by several researchers, such as Shayesteh Bilondi et al. [8] and Wong [7]. The effect of the column web panel was not modeled in previous studies. Therefore, in this paper, the column web panel is not modeled to make the ability to validate the results of structural modeling with the results of previous research. The structure is a six-story steel moment frame, which has been known as a mid-rise structure. Since the moment-resisting frame should be able to resist the lateral load induced by the severe earthquake; therefore, here, the structure is equipped with the TMD. The TMD system is selected since it is easily installed on the roof of the structure, and no need for external energy to work during the earthquake. Therefore, it can be economical.
As shown in Fig. 2, the steel moment-resisting frame has 3 bays. The OpenSees software was used by Mazzoni et al. [29] to perform the nonlinear dynamic analysis of the special moment-resisting frame. They used elastic beamcolumn elements. At both ends of each element, a nonlinear spring with length equal to zero has been attached to the element that provides the concentrated plasticity model for the element (see Fig. 3). The modified IbarraMedina-Krawinkler deterioration model is used to simulate the bilinear hysteretic behavior of springs (hings) [30] (see Fig. 4). A fictitious lean-on column has also been utilized in the analytical model to consider interior simple gravity frames' effect [31].

Because the frame elements are serially connected to the rotational springs, the stiffness of these members should be corrected so that the stiffness of the set is equated with the stiffness of the actual member. The value of $n$ is considered to be equal to 10 (i.e., $n=10$ ). This allows the damping to be assigned to the elastic elements. The stiffness of the elastic element should also be equal to $(n+1) / n$ greater than the stiffness of the actual element of the frame until the equivalent stiffness of
Fig. 2 A six-story steel moment-resisting frame

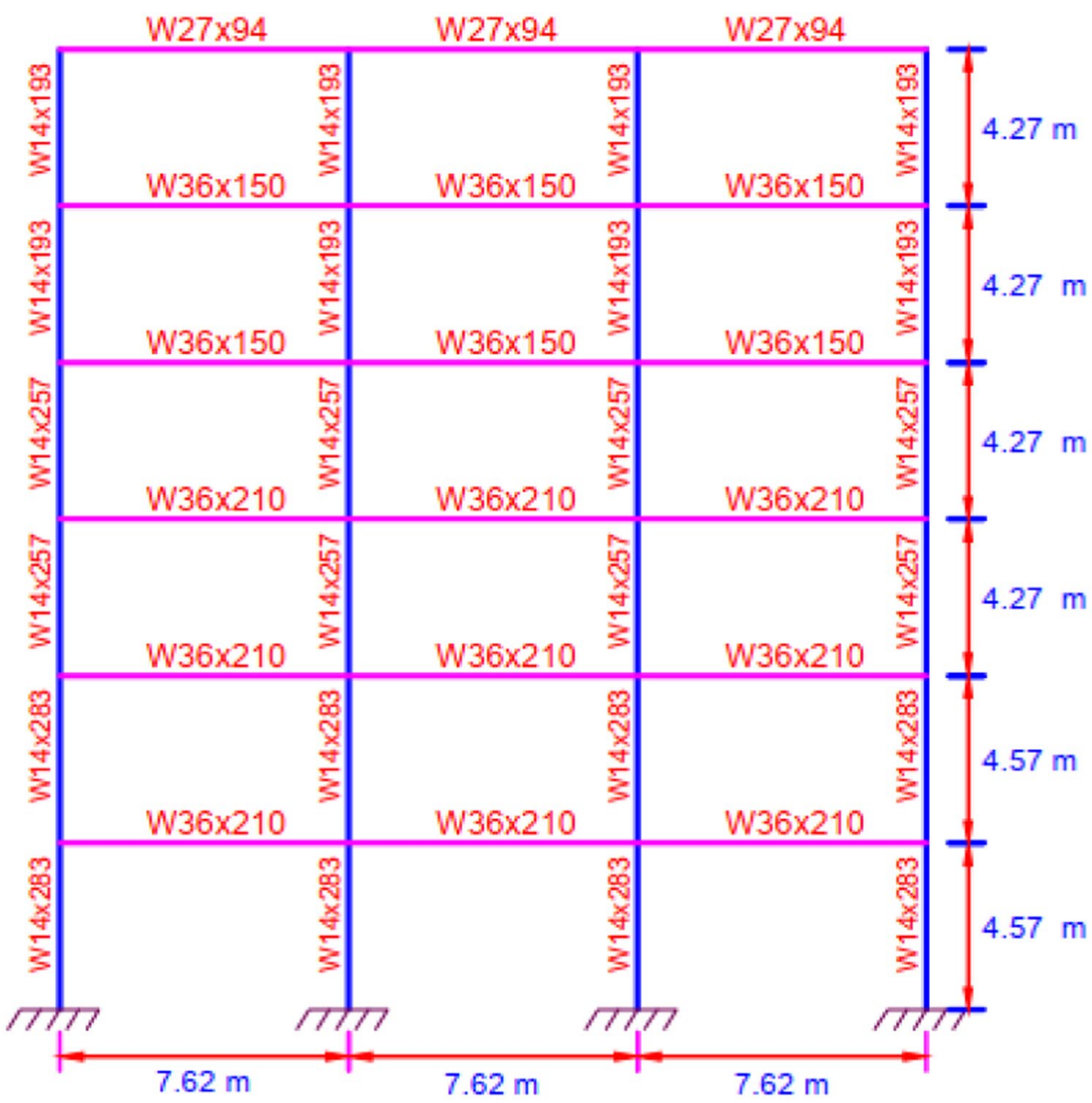

SN Applied Sciences 


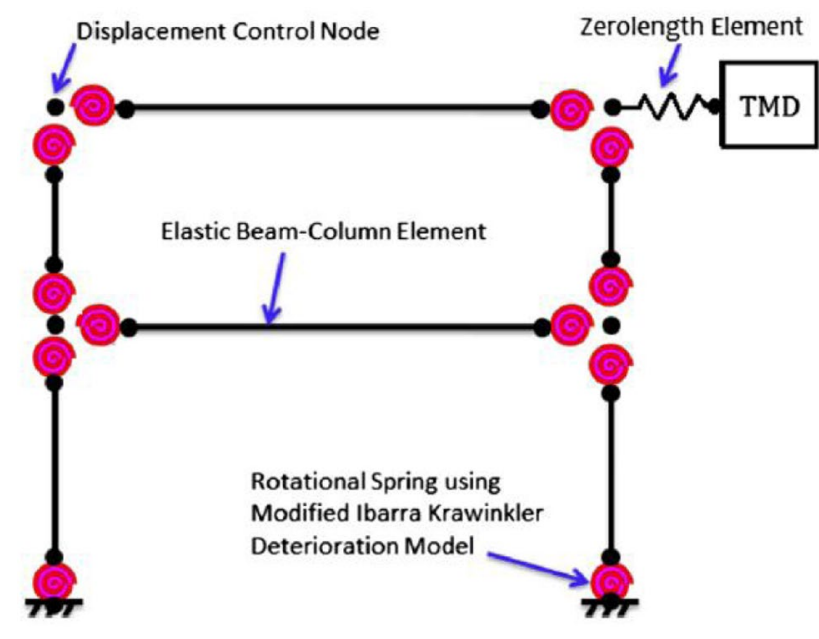

Fig. 3 A one-bay special moment-resisting frame that is controlled with a TMD system with lumped plasticity model [8]

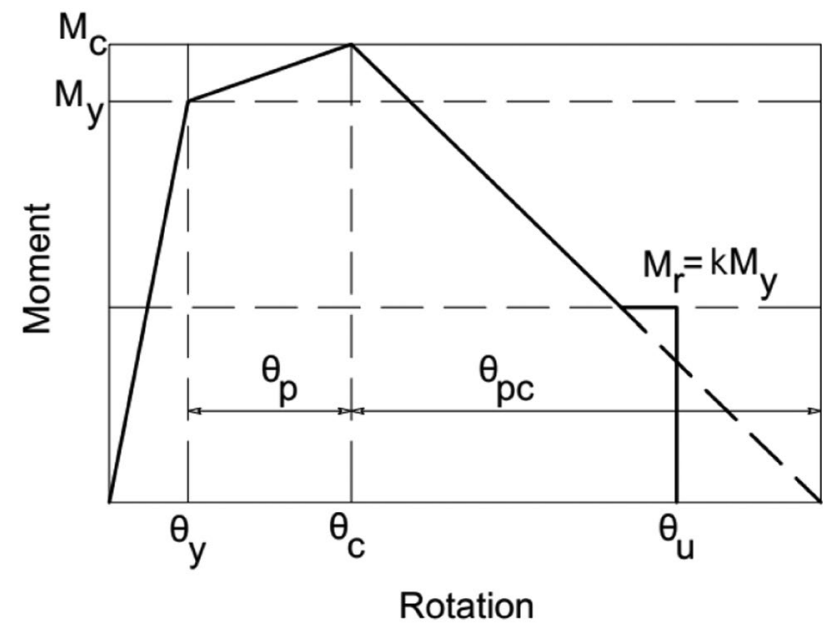

Fig. 4 The moment-rotation curve for the modified IMK deterioration model $[21,22]$

the element is equal to the real stiffness. The moment of inertia is also considered to multiply $(n+1) / n$ by the moment of inertia in the actual elements. The stiffness coefficient of the strain of the plastic joints should also be corrected following Eq. (5) to uniformize the nonlinear behavior considered in the spring with the actual action of the frame, [32]

$\alpha_{s, \text { sprong }}=\left(\frac{\alpha_{s, \text { mem }}}{1+n \times\left(1-\alpha_{s, \text { mem }}\right)}\right)$

where $\alpha_{s, m e m}$ and $\alpha_{s, \text { sprong }}$ show the strain hardening factor of the actual element of the frame and the strain hardening factor of the rotational spring, respectively. Except for the fictitious lean-on columns that are pinned at the base of the structure, the rest of the columns are fixed at the bottom of the structure.

In this paper, the required parameters in definition, the behavioral curve of the rotational springs, have been calculated based on the proposed formulae by Lignos et al. [22].

\section{Verification}

\subsection{Pushover analysis}

Pushover is a non-linear static analysis known as a powerful tool for assessing the seismic performance of a structure. Pushover is composed of a series of static incremental analyses that result in constructing a structural curve and thus provide a good view of structural behavior. In this curve, the base shear value is plotted against the roof displacement of the structure, leading to the calculation of the target displacement of the structure. The target displacement indicates the displacement of the structure experiences in the design earthquake. The results obtained from Laura's study [29] (a two-story frame structure with lumped plasticity model) are compared with those obtained in the present study. Figure 5 shows that the analysis done with the codes written in this study is identical to the results provided by Laura Eads (see Fig. 5). The studied building is then analyzed with Sap2000 and OpenSess software, and their result is shown in Fig. 6. Based on this figure, the ultimate and yield displacements are $760(\mathrm{~mm})$ and $210(\mathrm{~mm})$, respectively.

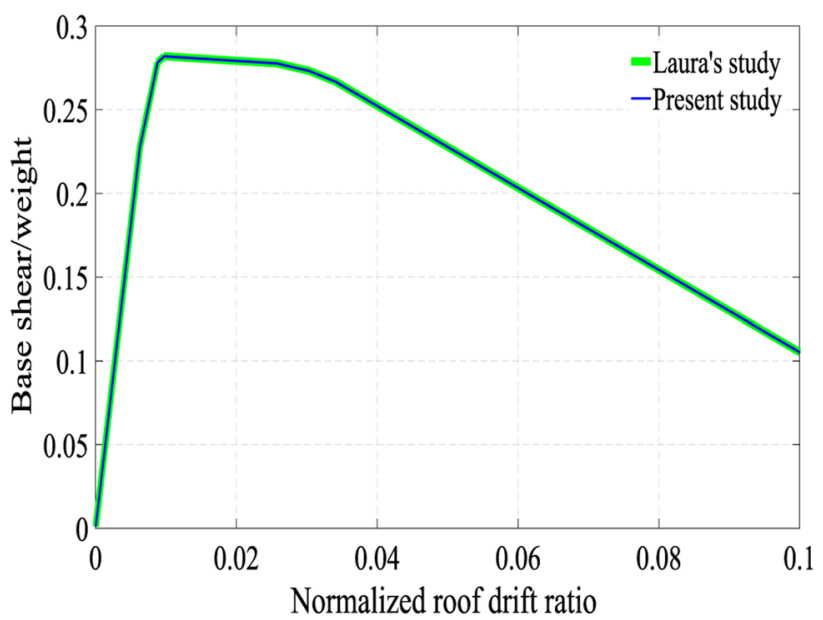

Fig. 5 A comparison between the results of the pushover analysis in the two-story frame provided by Laura Eads and the present study 


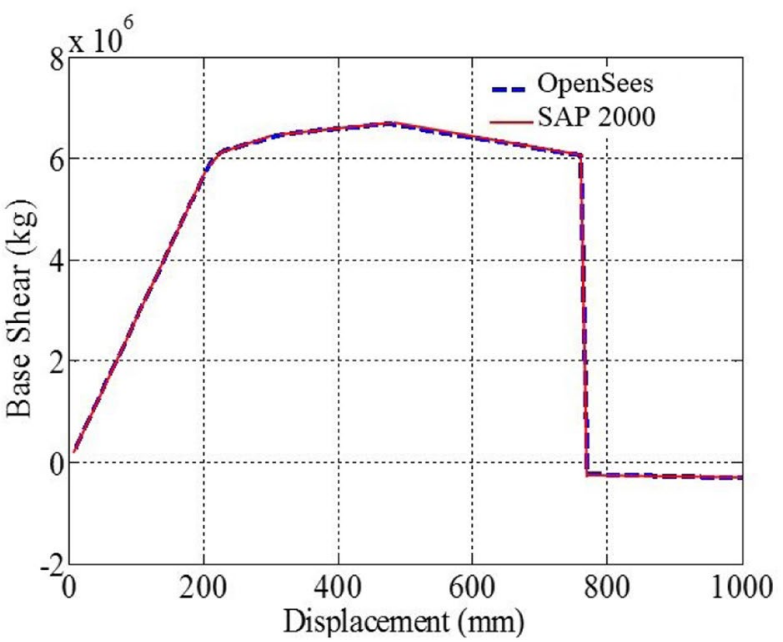

Fig. 6 A competition between the pushover curves obtained from SAP 2000 and OpenSees software

Table 2 A comparison between the first six natural frequencies of the studied building

\begin{tabular}{llll}
\hline $\begin{array}{l}\text { Mode num- } \\
\text { ber }\end{array}$ & \multicolumn{2}{l}{ Natural periods of vibration (sec) } \\
\cline { 2 - 4 } & Wong [7] & $\begin{array}{l}\text { Shayesteh Bilondi } \\
\text { et al. [8] }\end{array}$ & Present study \\
\hline 1 & 1.22 & 1.24 & 1.24 \\
2 & 0.44 & 0.45 & 0.46 \\
3 & 0.25 & 0.25 & 0.25 \\
4 & 0.18 & 0.18 & 0.18 \\
5 & 0.14 & 0.14 & 0.14 \\
6 & 0.11 & 0.11 & 0.11 \\
\hline
\end{tabular}

\subsection{Dynamic analysis}

Here, a steel moment-resisting frame is considered. The structure has six stories. This frame has already been examined by Wong [7] and Shayesteh Bilondi et al. [8]. All beams are subjected to the uniform load with magnitude 21.89 $(\mathrm{kN} / \mathrm{m})$. Also, the mass of each story is considered to be equal to $300,000(\mathrm{~kg})$, and the damping ratio is considered to be $3 \%$. The values of elasticity modulus and yield stress of the materials are considered to be equal to 200,000 $(\mathrm{MPa})$ and $248.2(\mathrm{MPa})$, respectively. The natural frequencies of the building are shown in Table 2.

\section{Selection of the most suitable optimization method among the studied algorithms}

In general, meta-heuristic algorithms have a better performance rather than simple optimization algorithms. Almost all meta-heuristic algorithms are suitable for nonlinear models and optimization problems [33]. However, because of the wide range of the meta-heuristic algorithms presented in recent years, it is better to choose an algorithm having a high convergence rate and accuracy in minimizing the objective function (minimizing the ductility damage index). Thus, in this paper, four algorithms that have been known as GWO, AWPSO, ICA, and WCA algorithms are selected, and the best ones are chosen to minimize the ductility damage index. For this purpose, the Near- and Far-field ground motion records are selected from FEMA P695 [34] (13 far-field and 17 near-field earthquakes). Initially, all records are scaled to have PGA (peak ground acceleration) equal to $9.81\left(\mathrm{~m} / \mathrm{sec}^{2}\right)$. Then, the magnitude of the ductility damage index (DDI) is calculated for the studied frame without the TMD system subjected to all scaled earthquakes. Finally, the earthquakes that caused the highest DDI values are selected. Table 3 shows the properties of the selected earthquakes.

To find the most suitable optimization method among the studied algorithms, the Imperial Valley, Northridge, and Hector earthquakes are selected that make different values of DDI in the uncontrolled six-story

Table 3 Properties of the scaled earthquakes

\begin{tabular}{|c|c|c|c|c|c|c|}
\hline Earthquake & PGA $\left(\mathrm{m} / \mathrm{sec}^{2}\right)$ & $\begin{array}{l}\text { PGA/PGV } \\
\text { (g.sec/m) }\end{array}$ & $\begin{array}{l}\text { Strong ground motion } \\
\text { duration (sec) }\end{array}$ & $\begin{array}{l}\text { Predominant } \\
\text { period (sec) }\end{array}$ & $\begin{array}{l}\text { Total time dura- } \\
\text { tion }(\mathrm{sec})\end{array}$ & $\begin{array}{l}\text { Arias Inten- } \\
\text { sity (m/sec) }\end{array}$ \\
\hline Northridge & 9.81 & 0.591 & 7.23 & 0.70 & 19.9 & 9.83 \\
\hline Imperial Valley & 9.81 & 1.275 & 22.82 & 0.12 & 35.98 & 20.236 \\
\hline Hector & 9.81 & 1.020 & 11.67 & 0.22 & 45.3 & 11.784 \\
\hline Chi Chi & 9.81 & 0.63 & 28.55 & 1.08 & 89.995 & 12.29 \\
\hline Near-Duzce & 9.81 & 0.568 & 11.065 & 0.40 & 25.88 & 16.54 \\
\hline Loma Prieta & 9.81 & 0.888 & 8.985 & 0.40 & 25 & 25.73 \\
\hline Far-Duzce & 9.81 & 1.32 & 8.55 & 0.32 & 55.89 & 6.8114 \\
\hline San Fernando & 9.81 & 1.035 & 13.15 & 0.24 & 79.44 & 13.40 \\
\hline Superstition Hills & 9.81 & 0.7432 & 27.99 & 0.22 & 59.99 & 8.645 \\
\hline
\end{tabular}


Table 4 Optimum values achieved by the Imperial Valley earthquake

\begin{tabular}{llllll}
\hline Algorithm & The value of DDI & $\begin{array}{l}\text { The maximum } \\
\text { required iteration }\end{array}$ & $\begin{array}{l}K_{d} \\
(\mathrm{~N} / \mathrm{mm})\end{array}$ & $\begin{array}{l}\mathrm{C}_{d} \\
(\mathrm{~N} . \mathrm{sec} / \mathrm{mm})\end{array}$ & $\begin{array}{l}M_{d} \\
\left(\mathrm{~N} . \mathrm{sec}^{2} / \mathrm{mm}\right)\end{array}$ \\
\hline GWO & 0.5118 & 29 & 167.9 & 271.7 & 176.3 \\
AWPSO & 0.5163 & 30 & 230.6 & 263.4 & 139.5 \\
ICA & 0.5119 & 25 & 195.7 & 266.4 & 160 \\
WCA & 0.5112 & 13 & 161 & 272.9 & 180 \\
\hline
\end{tabular}

Table 5 Optimum values achieved by the Northridge earthquake

\begin{tabular}{llllll}
\hline Algorithm & The value of DDI & $\begin{array}{l}\text { The maximum } \\
\text { required iteration }\end{array}$ & $\begin{array}{l}K_{d} \\
(\mathrm{~N} / \mathrm{mm})\end{array}$ & $\begin{array}{l}C_{d} \\
(N . \mathrm{sec} / \mathrm{mm})\end{array}$ & $\begin{array}{l}M_{d} \\
\left(\mathrm{~N} \cdot \mathrm{sec}^{2} / \mathrm{mm}\right)\end{array}$ \\
\hline GWO & 0.913960 & 26 & 405.6 & 327.1 & 180 \\
AWPSO & 0.916413 & 29 & 386.6 & 379 & 180 \\
ICA & 0.913957 & 29 & 405.4 & 328 & 180 \\
WCA & 0.913956 & 15 & 405.4 & 328.5 & 180 \\
\hline
\end{tabular}

Table 6 Optimum values achieved by the Hector earthquake

\begin{tabular}{llllll}
\hline Algorithm & The value of DDI & $\begin{array}{l}\text { The maximum } \\
\text { required iteration }\end{array}$ & $\begin{array}{l}K_{d} \\
(\mathrm{~N} / \mathrm{mm})\end{array}$ & $\begin{array}{l}C_{d} \\
(\mathrm{~N} \cdot \mathrm{sec} / \mathrm{mm})\end{array}$ & $\begin{array}{l}M_{d} \\
\left(\mathrm{~N} \cdot \mathrm{sec}^{2} / \mathrm{mm}\right)\end{array}$ \\
\hline GWO & 0.7961 & 19 & 403.3 & 2000 & 180 \\
AWPSO & 0.7961 & 20 & 405.6 & 2000 & 180 \\
ICA & 0.7960 & 19 & 403.7 & 191 & 180 \\
WCA & 0.7955 & 14 & 405 & 1172.2 & 180 \\
\hline
\end{tabular}

Table 7 The values of the ductility damage index based on different algorithms

\begin{tabular}{|c|c|c|c|c|c|c|c|c|c|}
\hline \multirow[t]{3}{*}{ Earthquake } & \multicolumn{5}{|c|}{ Ductility damage index } & \multirow{2}{*}{\multicolumn{4}{|c|}{ Reduction percentage (\%) }} \\
\hline & \multirow[t]{2}{*}{ Without TMD } & \multicolumn{4}{|c|}{ With TMD } & & & & \\
\hline & & GWO & AWPSO & ICA & WCA & GWO & AWPSO & ICA & WCA \\
\hline Imperial Valley & 0.14 & 0.072 & 0.073 & 0.072 & 0.072 & $\% 48.6$ & $\% 47.8$ & $\% 48.6$ & $\% 48.6$ \\
\hline Northridge & 1.116 & 1.0197 & 1.0225 & 1.0197 & 1.0197 & $\% 8.6$ & $\% 8.37$ & $\% 8.6$ & $\% 8.6$ \\
\hline Hector & 0.65 & 0.5 & 0.5 & 0.5 & 0.5 & $\% 23$ & $\% 23$ & $\% 23$ & $\% 23$ \\
\hline
\end{tabular}

moment-resisting frame. Also, these earthquakes have different values of the PGA/PGV ratio based on Chandler's classification $[6,35]$. The three different categories have been used in this paper.

Finally, the structure is controlled using the optimally designed TMD system. The optimization process results for the 6-story steel frame using the GWO, AWPSO, ICA, and WCA algorithms subjected to the Imperial Valley, Northridge, and Hector earthquakes are shown in Tables 4, 5, 6 and 7. As it is clear from Tables $(4,5$ and 6$)$, the WCA algorithm has achieved the optimal values in much less iteration. Also, using this algorithm, the value of the objective function becomes minimum.

As a result, it can be concluded that the WCA algorithm has a higher convergence rate and optimal value compared to the rest of the algorithms in reaching the optimal values.

Therefore, the WCA algorithm is chosen as the most suitable metaheuristic algorithm to determine the optimal parameters of a TMD system to minimize the ductility damage index.

\section{Results}

In this section, the 6-story steel frame is subjected to the selected earthquakes (see Table 3), and the optimal values for the TMD system are calculated using the WCA algorithm. The optimal values for the TMD system are shown in Table 8. Based on this table, the TMD system has been 
able to reduce the ductility damage index, and therefore it enhances the seismic performance of the structure.

Also, the roof displacement time history and drift ratio for the stories of the buildings controlled (with TMD) and uncontrolled (without TMD) subjected to some of the earthquakes are shown in Figs. 7, 8 and 9. Based on Table 8, it can be found that the WCA algorithm has been able to reduce the ductility damage index of the studied building under the Chi-Chi, Near-Duzce, and Loma Prieta earthquakes. Therefore, it could increase the structure's seismic performance while reducing the ductility damage index values for the Far-Duzce, San Fernando, and Superstition Hills earthquakes are not impressive. It should be noted that for all of these analyses, the TMD system is located on the roof of the structure.

According to Table 8, the ductility damage index for the uncontrolled structure under the Far-Duzce earthquake is equal to 0.159 , which indicates a slight failure of the structure. However, according to Fig. 7, the TMD system decreased the roof displacement values and the drift ratio of the structure. This has improved the seismic performance of the structure, even for a minor earthquake. According to Fig. 8, this is also repeated for the Near-Duzce earthquake with a ductility damage index equal to 0.412 . Figure 9 shows the roof displacement and drift ratio for the Chi-Chi earthquake with a ductility damage index equal to
Table 8 Optimum values for the TMD system obtained by WCA

Fig. 7 A comparison between the roof displacement and drift ratio of the controlled and uncontrolled buildings under the Far-Duzce earthquake

Fig. 8 A comparison between the roof displacement and drift ratio of the controlled and uncontrolled buildings under the Near-Duzce earthquake

\begin{tabular}{|c|c|c|c|c|c|c|}
\hline \multirow[t]{2}{*}{ Earthquake } & \multicolumn{3}{|c|}{ Optimum achieved values } & \multicolumn{2}{|c|}{ Ductility damage index } & \multirow{2}{*}{$\begin{array}{l}\text { Reduction } \\
\text { percentage } \\
(\%)\end{array}$} \\
\hline & $\begin{array}{l}K_{d} \\
(\mathrm{~N} / \mathrm{mm})\end{array}$ & $\begin{array}{l}C_{d} \\
(N . s e c / m m)\end{array}$ & $\begin{array}{l}M_{d} \\
\left(N \cdot \sec ^{2} / \mathrm{mm}\right)\end{array}$ & Without TMD & With TMD & \\
\hline Loma Prieta & 405.1 & 1496.4 & 180 & 0.47 & 0.24 & 49.1 \\
\hline Near-Duzce & 405.1 & 2000 & 180 & 0.412 & 0.249 & 39.56 \\
\hline Chi Chi & 405.0 & 2000 & 180 & 0.900 & 0.675 & 25.03 \\
\hline Superstition Hills & 405.5 & 599.9 & 180 & 0.425 & 0.387 & 8.79 \\
\hline San Fernando & 406.3 & 283.1 & 180 & 0.470 & 0.454 & 3.39 \\
\hline Far-Duzce & 405.5 & 244.6 & 180 & 0.159 & 0.155 & 3.12 \\
\hline
\end{tabular}
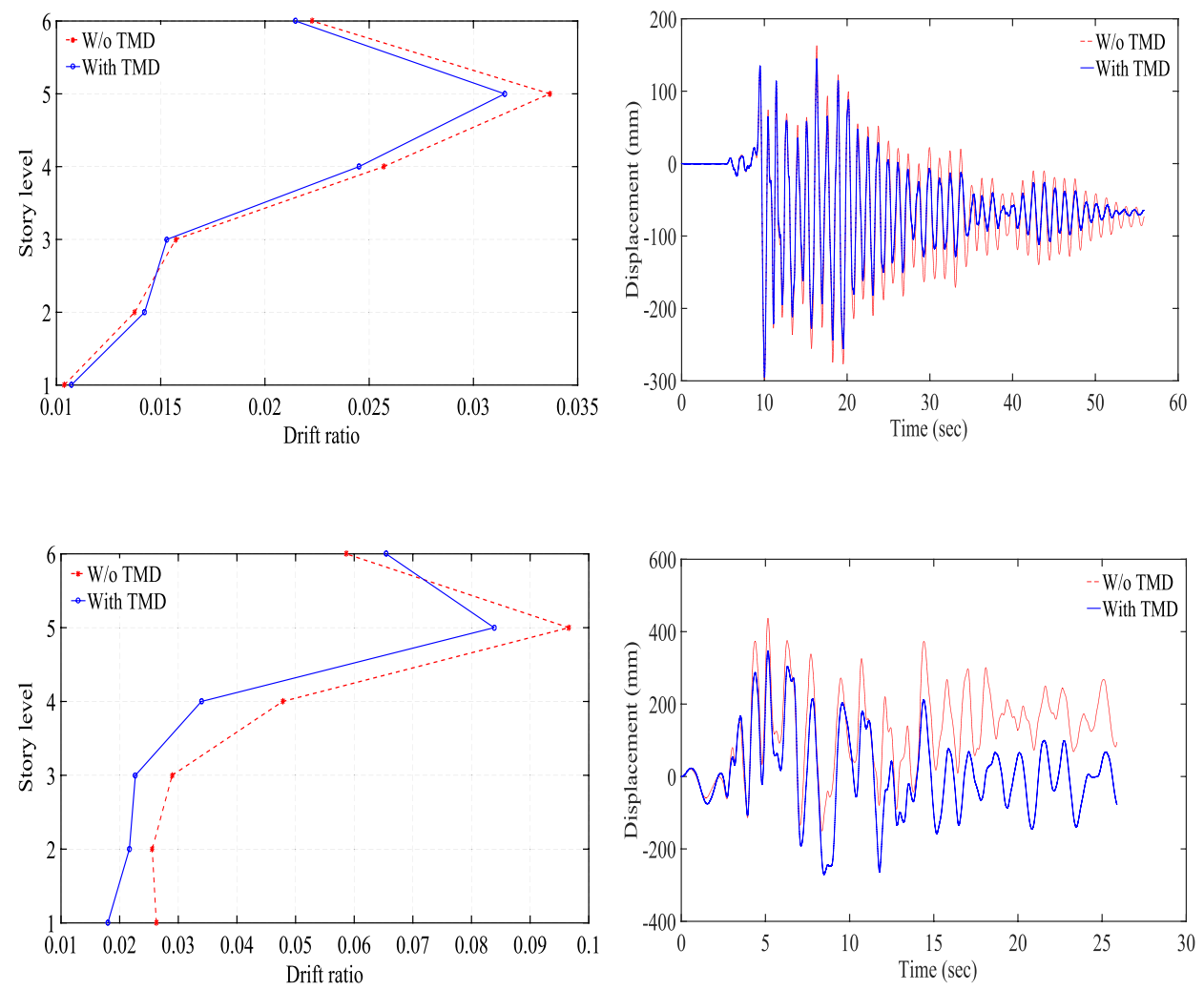
0.9. This figure indicates a reduction in the seismic parameters of the structure for a strong earthquake.

Based on Figs. 7, 8 and 9, it can be concluded that the TMD system has been able to reduce the ductility damage index, the roof displacement, and the drift ratio of stories. The TMD system can also force the structure to vibrate within its elastic range (e.g., see Figs. 8 and 9 in which the drift ratio and maximum displacement of the stories have been reduced). In fact, for some studied earthquakes (see Figs. 8 and 9), the TMD system could force the structure to oscillate about its initial equilibrium position. Therefore, the TMD system can significantly enhance the seismic behavior of the structure. Also, it can be concluded that the values of the roof displacement and drift ratio have simultaneously reduced for the Far-Duzce, Near-Duzce, Chi-Chi, San Fernando, Superstition Hills, and Northridge earthquakes. For the Loma Prieta earthquake, although the value of the ductility damage index is significantly reduced (49.1\%), the amount of the drift ratio has increased at the bottom of the controlled structure. This process has been changed concerning Hector's earthquake, and the value of the drift ratio has increased for the above stories of the controlled structure. However, for this earthquake, DDI reduced by $23 \%$. For the Imperial Valley earthquake, although the value of the ductility damage index is significantly reduced $(48 \%)$, the amount of roof displacement has no significant changes in the controlled structure. As previously mentioned, the TMD system is located on the roof of the structure. Therefore, for the Loma Prieta and Hector earthquakes, the seismic performance of the structure is studied by changing the position of the TMD system. The maximum value of the drift ratio occurs in the third story of the controlled structure when it is subjected to the Loma Prieta earthquake. Therefore, the TMD system is located on the third story. The optimal values of the TMD system are determined so that the ductility damage index of the structure is minimized. The results are shown in Fig. 10 and Table 9.
Fig. 9 A comparison between the roof displacement and drift ratio of the controlled and uncontrolled buildings under the Chi-Chi earthquake
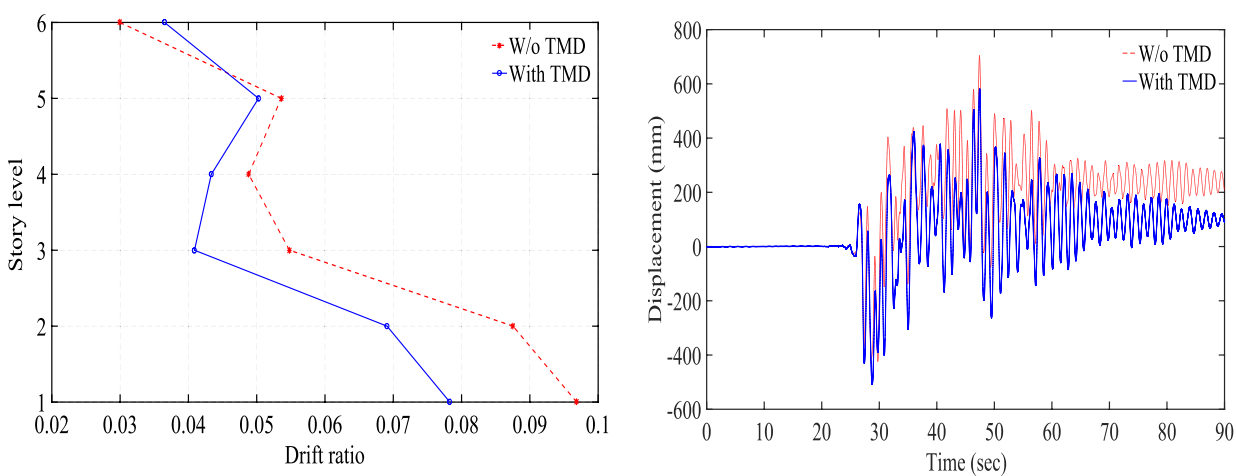

Fig. 10 A comparison between the roof displacement, third story displacement, and drift ratio of the controlled and uncontrolled buildings under the Loma Prieta earthquake when the TMD system has been located on the third story
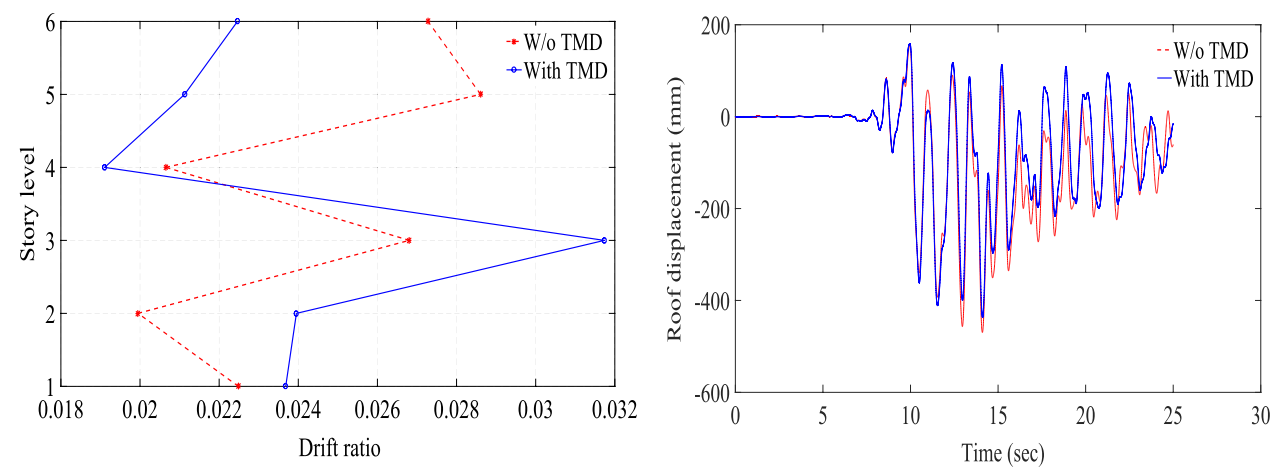

Table 9 Optimum values achieved for TMD installed on the third floor under the Loma Prieta and Hector earthquakes

\begin{tabular}{lllllll}
\hline Earthquake & $\begin{array}{l}K_{d} \\
(\mathrm{~N} / \mathrm{mm})\end{array}$ & $\begin{array}{l}C_{d} \\
(\mathrm{~N} . \mathrm{sec} / \mathrm{mm})\end{array}$ & $\begin{array}{l}M_{d} \\
\left(\mathrm{~N} . \mathrm{sec}^{2} / \mathrm{mm}\right)\end{array}$ & $\begin{array}{l}\text { DDl for the } \\
\text { uncontrolled } \\
\text { structure }\end{array}$ & $\begin{array}{l}\text { DDI for the con- } \\
\text { trolled structure }\end{array}$ & $\begin{array}{l}\text { Reduction } \\
\text { percentage } \\
(\%)\end{array}$ \\
\hline Loma Prieta & 404.94 & 2000 & 180 & 0.47 & 0.41 & 12.55 \\
Hector & 406 & 318.87 & 180 & 0.65 & 0.616 & 5.39 \\
\hline
\end{tabular}


Based on Tables 8 and 9 and Fig. 10, it can be concluded that for the Loma Prieta earthquake, the percentage reduction in DDI decreases when the position of the TMD system moves from the roof to the third story. Also, the maximum values of the roof displacement increase by changing the location of the TMD system. However, the maximum value of the drift ratios decreases, and in general, the seismic performance of the structure has not been improved by changing the position of the TMD system.

Finally, to show the ability of the TMD system in improving the seismic performance of the structure, the story's damage to the controlled and uncontrolled structure is shown in Figs. 11 and 12.

Based on these figures, the TMD system has effectively reduced the story damage of the studied structure. Here, an artificial earthquake is computed based on Refs. [36, 37] to investigate the ability of a TMD system to reduce DDI:

$S_{\text {Kanai-Tajimi }}(\omega)=S_{0}\left[\frac{\omega_{g}^{4}+\left(2 \times \omega_{g} \times \xi_{g} \times \omega\right)^{2}}{\left(\omega^{2}-\omega_{g}^{2}\right)^{2}+\left(2 \times \omega_{g} \times \xi_{g} \times \omega\right)^{2}}\right]$

$S_{0}=\frac{0.03 \times \xi_{g}}{\pi \times \omega_{g} \times\left(4 \times \xi_{g}^{2}+1\right)}$

where $S_{0}$ is the intensity of the power spectral density function (PSDF) $[36,38]$. Also, $\omega_{g}$ shows the frequency of the considered soil. The $\xi_{q}$ parameter represents the damping of soil. Here, the values of parameters $\omega_{g}$ and $\xi_{g}$ are selected based on Ref. [39]. These parameters are equal to $25.13(\mathrm{rad} / \mathrm{sec})$ and 0.8 , respectively. These quantities indicate that the soil is stiff. Figure 13 and Table 10 show the acceleration time history and properties of the artificial earthquake. The total time duration of the artificial

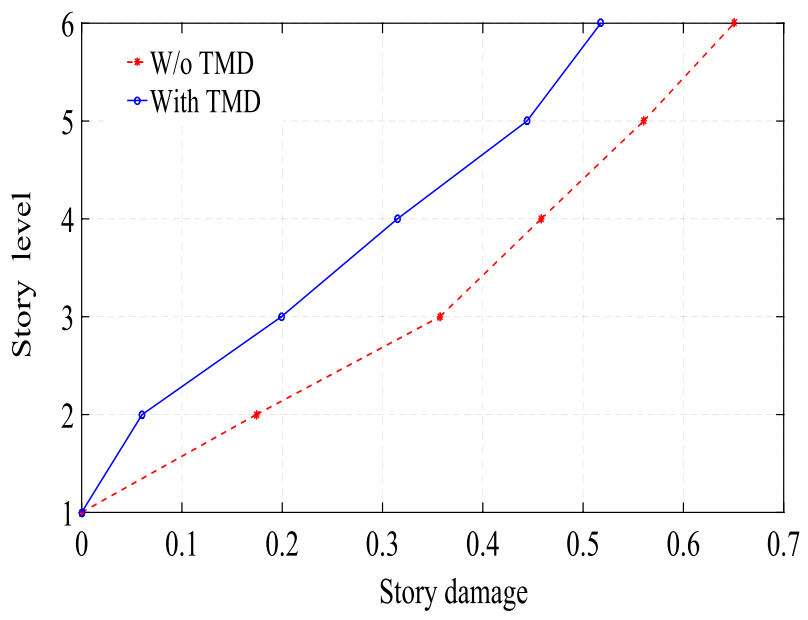

Fig. 11 Story damage for the controlled and uncontrolled buildings under the Hector earthquake when the TMD system has been located on the roof

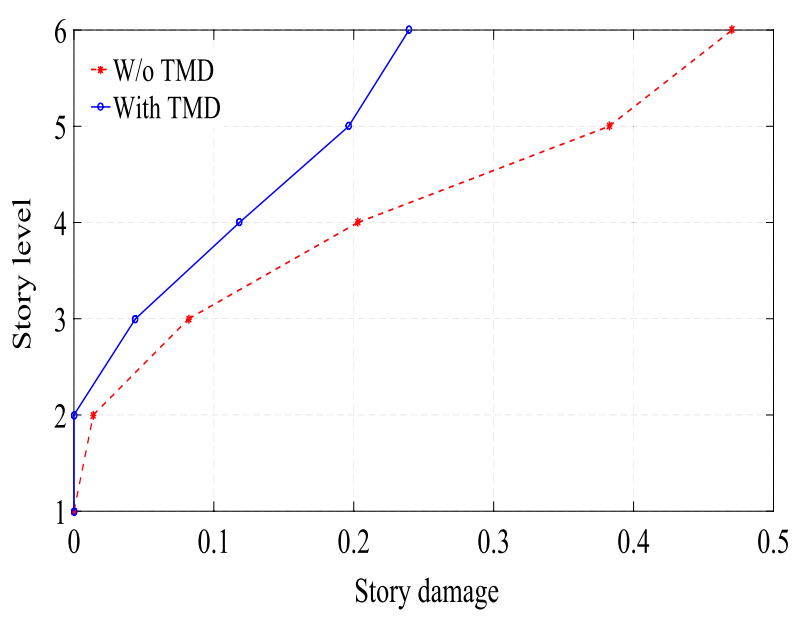

Fig. 12 Story damage for the controlled and uncontrolled buildings under the Loma Prieta earthquake when the TMD system has been located on the roof

earthquake is $19.98(\mathrm{sec})$, in which 18 (sec) of this time has been dedicated to the strong ground motion. The purpose of this section is to investigate the effect of the strong ground motion duration in controlling the responses of the structure subjected to an earthquake that has a long duration for strong ground motion.

Therefore, the six-story steel frame is considered excited by the artificial earthquake, and the optimal parameters of the TMD system are calculated using the WCA algorithm. The optimal values are shown in Table 11. Also, the roof displacement time history and the drift ratio for the buildings' stories with TMD and without TMD are shown in Fig. 14. Based on Table 11, it can be found that the optimal values for the parameters of the TMD system obtained with the WCA have been able to reduce the ductility damage index of the studied building under the artificial earthquake. Also, it can be concluded that the value of the ductility damage index is

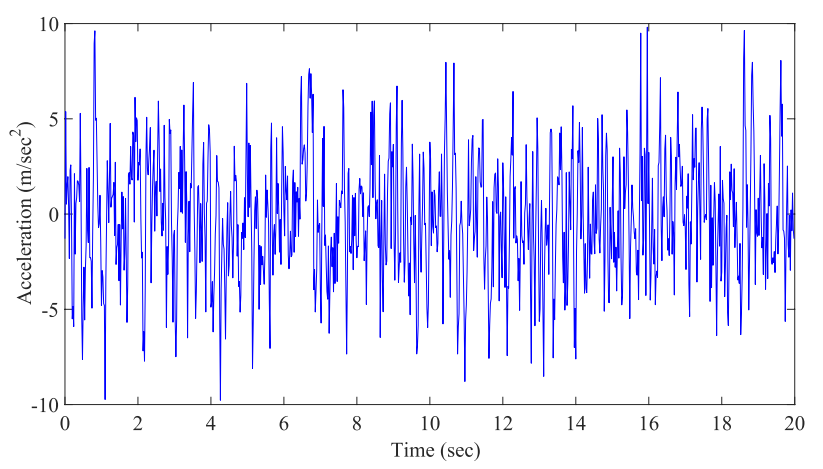

Fig. 13 Time history acceleration for the artificial earthquake 
Table 10 Characteristics of the artificial earthquake

\begin{tabular}{|c|c|c|c|c|c|c|}
\hline Earthquake & PGA $\left(\mathrm{m} / \mathrm{sec}^{2}\right)$ & PGA/PGV (g.sec/m) & $\begin{array}{l}\text { Strong ground } \\
\text { motion duration } \\
(\mathrm{sec})\end{array}$ & $\begin{array}{l}\text { Predominant } \\
\text { period (sec) }\end{array}$ & $\begin{array}{l}\text { Total time duration } \\
(\mathrm{sec})\end{array}$ & $\begin{array}{l}\text { Arias Intensity (m/ } \\
\mathrm{sec})\end{array}$ \\
\hline $\begin{array}{l}\text { Artificial earth- } \\
\text { quake }\end{array}$ & 9.81 & 0.2064 & 18 & 0.2 & 19.98 & 33.31 \\
\hline
\end{tabular}

Table 11 Optimum values for the TMD system obtained by WCA

\begin{tabular}{|c|c|c|c|c|c|c|}
\hline \multirow[t]{2}{*}{ Earthquake } & \multicolumn{3}{|c|}{ Optimum achieved values } & \multicolumn{2}{|c|}{ Ductility damage index } & \multirow[t]{2}{*}{ Reduction percentage (\%) } \\
\hline & $\begin{array}{l}K_{d} \\
(\mathrm{~N} / \mathrm{mm})\end{array}$ & $\begin{array}{l}C_{d} \\
(N . s e c / m m)\end{array}$ & $\begin{array}{l}M_{d} \\
\left(N \cdot \sec ^{2} / \mathrm{mm}\right)\end{array}$ & Without TMD & With TMD & \\
\hline Artificial Earthquake & 405.2 & 2000 & 180 & 0.786 & 0.429 & 45.4 \\
\hline
\end{tabular}

Fig. 14 A comparison between the roof displacement and drift ratio of the studied buildings under the artificial earthquake
Table 12 Optimum values for the TMD system obtained by WCA under the artificial earthquake for the different positions of the TMD system
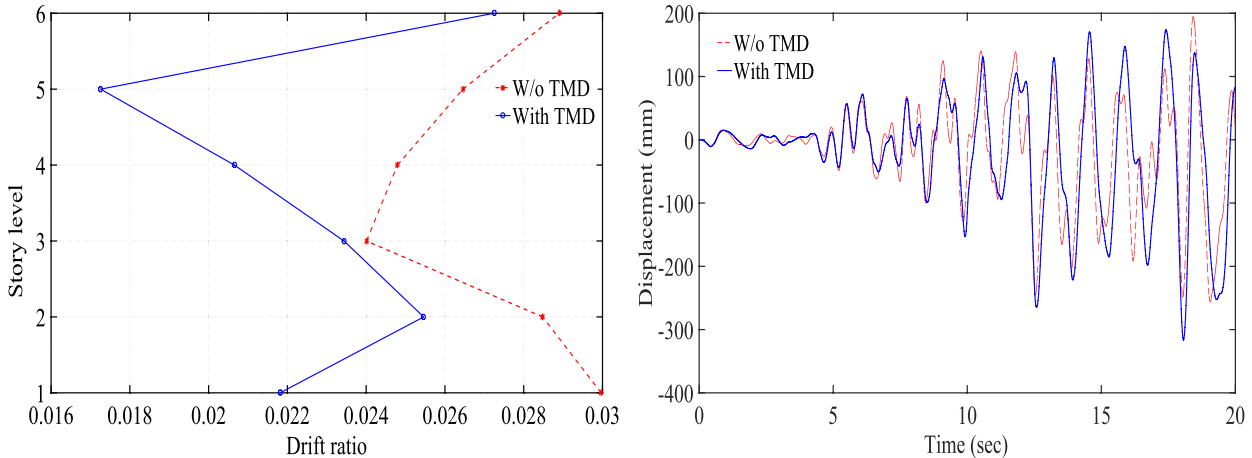

\begin{tabular}{|c|c|c|c|c|c|c|}
\hline \multirow[t]{2}{*}{ Location of the TMD } & \multicolumn{3}{|c|}{ Optimum achieved values } & \multicolumn{2}{|c|}{ Ductility damage index } & \multirow{2}{*}{$\begin{array}{l}\text { Reduction } \\
\text { percentage } \\
\text { (\%) }\end{array}$} \\
\hline & $\begin{array}{l}K_{d} \\
(\mathrm{~N} / \mathrm{mm})\end{array}$ & $\begin{array}{l}C_{d} \\
(N . s e c / m m)\end{array}$ & $\begin{array}{l}M_{d} \\
\left(N \cdot \sec ^{2} / \mathrm{mm}\right)\end{array}$ & Without TMD & With TMD & \\
\hline Story 6th & 405.2 & 2000 & 180 & 0.786 & 0.429 & 45.4 \\
\hline Story 5th & 404.12 & 2000 & 180 & 0.786 & 0.491 & 37.54 \\
\hline Story 4th & 404.99 & 2000 & 180 & 0.786 & 0.552 & 29.69 \\
\hline Story 3th & 405.14 & 2000 & 180 & 0.786 & 0.656 & 16.49 \\
\hline Story 2th & 405.15 & 389.67 & 180 & 0.786 & 0.724 & 7.84 \\
\hline Story 1 th & 405.35 & 199.55 & 180 & 0.786 & 0.816 & -3.87 \\
\hline
\end{tabular}

significantly reduced (45.4\%), and the amount of the roof displacement and drift ratio have changed considerably in the controlled structure.

It should be noted that in the examples mentioned above, the TMD system has been placed on the roof story. In this section, the WCA is used to compute the optimum values for the parameters of the TMD system when the position of the TMD system changes from the bottom to the top story. Table 12 shows the optimum values for the parameters of the TMD system and the reduction percentage of DDI. Based on this table, the roof story is the best candidate for the location of the TMD system.

Also, a comparison between the drift ratio, maximum story displacement, and story damage is depicted in Fig. 15. Based on this figure, the roof is selected as the best candidate for the placement of the TMD system under the artificial earthquake since it has the minimum story displacement and damage. 
Fig. 15 A comparison between the maximum stories displacement, stories damage, and drift ratio of the controlled and uncontrolled buildings under the artificial earthquake when the TMD system has been located at different stories
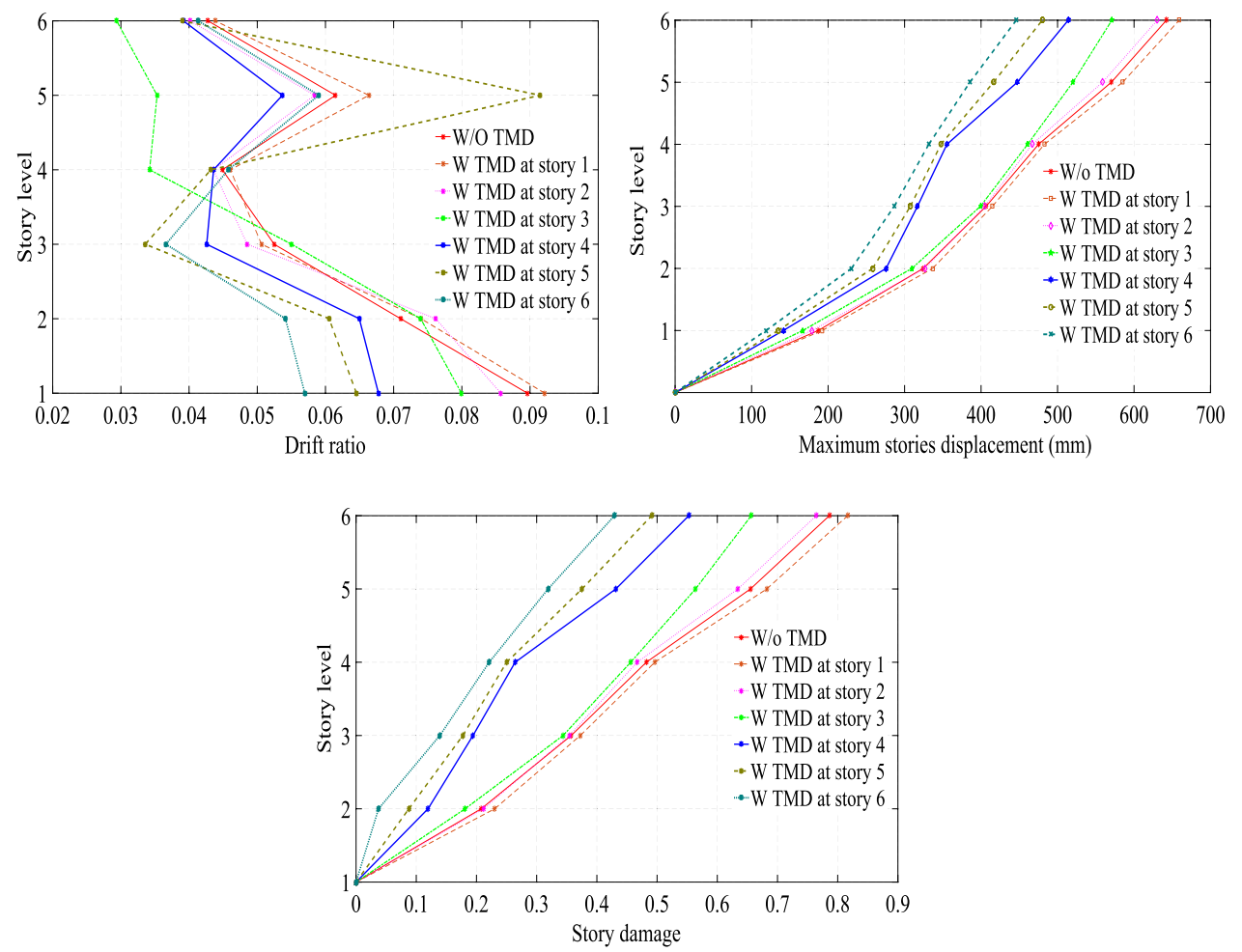

\section{Conclusion}

Here, the optimum values for the parameters of a TMD system are calculated to increase the seismic performance of the structure using minimizing the ductility damage index. A six-story frame is selected and modeled with the OpenSees software. For this purpose, the frame is modeled nonlinearly by a lumped plasticity model using the IMK model. In the first part of the research, the most suitable algorithm is selected among different optimization meta-heuristic algorithms based on the convergence rate and the objective function. In this process, the water cycle algorithm has shown the best results. In the second part of the research, using the water cycle algorithm, the optimal parameters of the TMD are calculated in such a way that the ductility damage index is minimized in the six-story structure under the earthquake loads. Therefore, the OpenSees software is used to perform the nonlinear dynamic analysis. Also, by linking the OpenSees and Matlab software, the optimum values for the parameters of the TMD system are computed to minimize the ductility damage index. The results show that the optimum values for the parameters of the TMD system obtained with the WCA could appropriately decrease the ductility damage index. Simultaneously, it can enhance the seismic performance of the structure to reduce the displacement, story damage, and drift ratio of the stories for the really happened earthquake and artificial earthquake with the long duration of the strong ground motion. In the third part of the research, the TMD system is placed at each story from bottom to the top. The optimum values for the parameters of the TMD system are computed with WCA so that the ductility damage index is minimized. The results show that the highest floor is the best place to install the TMD system.

Besides, the TMD system can force the structure to vibrate within its elastic range in which the drift ratio and maximum displacement of the stories have been reduced. Also, the TMD system could force the structure to oscillate about its initial equilibrium position. Besides, according to design regulations, one of the most important and necessary controls in steel structures is controlling drift and displacement of the structure. Excessive drift and displacement during an earthquake will cause additional shear force, moment, and torsions in the structural elements. One of the common ways of designing steel structures to reduce drift and displacement is to increase the dimensions of sections that resist the gravitational and lateral loads. This will cause additional costs and occupy useful spaces in the structures. However, in the method presented in this study, not only the damage of the structure is reduced, but also the drift and displacement are reduced.

\section{Compliance with ethical standard}

Conflict of interest The authors declare that they have no conflict of interest.

\section{SN Applied Sciences}


Ethical approval This article does not contain any studies with ani$\mathrm{mal} /$ human participants performed by any of the authors.

Open Access This article is licensed under a Creative Commons Attribution 4.0 International License, which permits use, sharing, adaptation, distribution and reproduction in any medium or format, as long as you give appropriate credit to the original author(s) and the source, provide a link to the Creative Commons licence, and indicate if changes were made. The images or other third party material in this article are included in the article's Creative Commons licence, unless indicated otherwise in a credit line to the material. If material is not included in the article's Creative Commons licence and your intended use is not permitted by statutory regulation or exceeds the permitted use, you will need to obtain permission directly from the copyright holder. To view a copy of this licence, visit http://creativecommons .org/licenses/by/4.0/.

\section{References}

1. Chey M-H, Kim J-U (2012) Parametric control of structural responses using an optimal passive tuned mass damper under stationary Gaussian white noise excitations. Front Struct Civil Eng 6:267-280. https://doi.org/10.1007/s11709-012-0170-x

2. Shoaei P, Oromi HT (2019) A combined control strategy using tuned liquid dampers to reduce displacement demands of base-isolated structures: a probabilistic approach. Front Struct Civil Eng 13:890-903. https://doi.org/10.1007/s1170 9-019-0524-8

3. Salvi J, Rizzi E (2015) Optimum tuning of tuned mass dampers for frame structures under earthquake excitation. Struct Control and Health Monit 22:707-725. https://doi.org/10.1002/stc.1710

4. Tigli OF (2012) Optimum vibration absorber (tuned mass damper) design for linear damped systems subjected to random loads. J Sound Vib 331:3035-3049. https://doi.org/10.1016/j. jsv.2012.02.017

5. Kamgar R, Khatibinia M, Khatibinia M (2019) Optimization criteria for design of tuned mass dampers including soil-structure interaction effect. Int J Optim Civil Eng 9:213-232

6. Kamgar R, Rahgozar R (2015) Determination of critical excitation in seismic analysis of structures. Earthq Struct 9:875-891. https ://doi.org/10.12989/eas.2015.9.4.875

7. Wong K (2008) Seismic energy dissipation of inelastic structures with tuned mass dampers. J Eng Mech 134:163-172. https://doi. org/10.1061/(ASCE)0733-9399

8. Shayesteh Bilondi MR, Yazdani H, Khatibinia M (2018) Seismic energy dissipation-based optimum design of tuned mass dampers. Struct Multidiscip Optim 58:2517-2531. https://doi. org/10.1007/s00158-018-2033-0

9. Shu Z, Li S, Sun X, He M (2019) Performance-based seismic design of a pendulum tuned mass damper system. J Earthq Eng 23:334-355. https://doi.org/10.1080/13632469.2017.1323042

10. Habibi A, Asadi K (2017) Development of drift-based damage index for reinforced concrete moment resisting frames with setback. Int J Civil Eng 15:487-498. https://doi.org/10.1007/s4099 9-016-0085-3

11. Habibi A, Izadpanah M, Yazdani A (2013) Inelastic damage analysis of RCMRFS using pushover method. Iranian J Sci Technol Transactions Civil Eng 37:345

12. Powell GH, Allahabadi R (1988) Seismic damage prediction by deterministic methods: concepts and procedures. Earthq Eng Struct Dynam 16:719-734. https://doi.org/10.1002/eqe.42901 60507
13. Williams MS, Sexsmith RG (1995) Seismic damage indices for concrete structure: a state-of-art review. Earthq Spectra 11:319349. https://doi.org/10.1193/1.1585817

14. Cosenza E, Manfredi G, Ramasco R (1993) The use of damage functionals in earthquake engineering: a comparison between different methods. Earthq Eng Struct Dynam 22:855-868. https ://doi.org/10.1002/eqe.4290221003

15. Park Y-J, Ang AH-S (1985) Mechanistic seismic damage model for reinforced concrete. J Struct Eng 111:722-739. https://doi. org/10.1061/(ASCE)0733-9445

16. Díaz SA, Pujades LG, Barbat AH, Hidalgo-Leiva DA, Vargas-Alzate YF (2018) Capacity, damage and fragility models for steel buildings: a probabilistic approach. Bull Earthq Eng 16:1209-1243. https://doi.org/10.1007/s10518-017-0237-0

17. Colombo A, Negro P (2005) A damage index of generalised applicability. Eng Struct 27:1164-1174. https://doi. org/10.1016/j.engstruct.2005.02.014

18. Zhang $X$, Wong KK, Wang $Y$ (2007) Performance assessment of moment resisting frames during earthquakes based on the force analogy method. Eng Struct 29:2792-2802. https://doi. org/10.1016/j.engstruct.2007.01.024

19. Gholizadeh S, Fattahi F (2018) Damage-controlled performance-based design optimization of steel moment frames. Struct Des Tall Special Build 27:e1498. https://doi.org/10.1002/ tal.1498

20. Danesh M, Gholizadeh S, Gheyratmand C (2019) Performancebased optimization and seismic collapse safety assessment of steel moment frames. Int J Optim Civil Eng 9:483-498

21. Ibarra LF, Medina RA, Krawinkler H (2005) Hysteretic models that incorporate strength and stiffness deterioration. Earthq Eng Struct Dynam 34:1489-1511. https://doi.org/10.1002/eqe.495

22. Lignos DG, Krawinkler H (2010) Deterioration modeling of steel components in support of collapse prediction of steel moment frames under earthquake loading. J Struct Eng 137:1291-1302. https://doi.org/10.1061/(ASCE)ST.1943-541X.0000376

23. Kamgar R, Rahgozar R (2016) A simple method for determining the response of linear dynamic systems. Asian J civil Eng 17:785-801

24. Dadkhah M, Kamgar R, Heidarzadeh H, Jakubczyk-Gałczyńska A, Jankowski R (2020) Improvement of performance level of steel moment-resisting frames using tuned mass damper system. Appl Sci 10:3403

25. Atashpaz-Gargari E, Lucas C (2007) Imperialist competitive algorithm: an algorithm for optimization inspired by imperialistic competition. IEEE Congr Evolut Comput 2007:4661-4667

26. Eberhart R, Kennedy J (1995) A new optimizer using particle swarm theory. Proceedings of the Sixth International Symposium on micro machine and human science

27. Mirjalili S, Mirjalili SM, Lewis A (2014) Grey wolf optimizer. Adv Eng Softw 69:46-61. https://doi.org/10.1016/j.advengsoft .2013.12.007

28. Eskandar H, Sadollah A, Bahreininejad A, Hamdi M (2012) Water cycle algorithm-a novel metaheuristic optimization method for solving constrained engineering optimization problems. Comput Struct 110:151-166. https://doi.org/10.1016/j.comps truc.2012.07.010

29. Mazzoni S, McKenna F, Scott MH, Fenves GL (2006) The open system for earthquake engineering simulation (OpenSEES) user command-language manual

30. Ibarra LF, Krawinkler H (2005) Global collapse of frame structures under seismic excitations. Pacific Earthquake Engineering Research Center Berkeley, CA

31. Xue Y (2012) Capacity design optimization of steel building frameworks using nonlinear time-history analysis. Doctor of Philosophy, Waterloo 
32. Krawinkler H, Zareian F, Lignos DG, Ibarra LF (2009) Prediction of collapse of structures under earthquake excitations. Proceedings of the 2nd International Conference on computational methods in structural dynamics and earthquake engineering (COMPDYN 2009), Rhodes, Greece, 22-24

33. Gandomi AH, Yang X-S, Talatahari S, Alavi AH (2013) Metaheuristic applications in structures and infrastructures. Elsevier, New York

34. FEMA-P695 (2009), Quantification of building seismic performance factors. Federal Emergency Management Agency. Washington, DC

35. Gholizadeh S, Salajegheh E (2010) Optimal seismic design of steel structures by an efficient soft computing based algorithm. J Constr Steel Res 66:85-95. https://doi.org/10.1016/j. jcsr.2009.07.006

36. Kanai K (1961) An empirical formula for the spectrum of strong earthquake motions (In Japanese). Bulletin Earthq Res Inst 39:85-95

37. Mohebbi M, Shakeri K, Ghanbarpour Y, Majzoub H (2013) Designing optimal multiple tuned mass dampers using genetic algorithms (GAs) for mitigating the seismic response of structures. J Vib Control 19:605-625. https://doi.org/10.1177/10775 46311434520

38. Tajimi H (1960) A statistical method of determing the maximum response of a building structure during an earthquake. Proceedings 2nd World Conference on Earthquake Engineering, 781-797

39. Wu J, Chen G, Lou M (1999) Seismic effectiveness of tuned mass dampers considering soil-structure interaction. Earthq Eng Struct Dynam 28:1219-1233. https://doi.org/10.1002/ (SICI)1096-9845(199911)

Publisher's Note Springer Nature remains neutral with regard to jurisdictional claims in published maps and institutional affiliations. 